\section{Architecture $\neq$ Landscape: The Case Against Hybridization}

\author{
ZACHARY TATE PORTER \\ University of Southern California
}

discourses and techniques associated with the design of ground. Instead, this essay advocates for the formal development of architecturalized systems of ground that mediate between the architectural object and the urban ground. Such an approach presents one potential alternative to disciplinary hybridization that allows architects to reclaim ground on their own terms.

\section{DISCIPLINARY FOUNDATIONS}

In order to understand the inherent difficulties of reintegrating architecture and landscape architecture, one must consider the intellectual foundations of each profession, especially regarding the modern city. As the American profession of landscape architecture emerged at the turn of the twentieth century, the future trajectory of city planning was uncertain. On the one hand, American architects like Daniel Burnham advocated for the City Beautiful style of planning, which emphasized grandiose compositions and visual monumentality. In his plans for cities like Chicago, San Francisco, and Manila, Burnham sought to redefine the city as a site for spectacle, rather than a center for industrial production and collective dwelling. Leading landscape architects like Frederick Law Olmsted, Jr., on the other hand, espoused a more pragmatic and socially conscious methodology for civic improvement. As the founding director of Harvard's landscape architecture program, Olmsted devised a pedagogical approach that prioritized the realities of the modern city over ideal compositions.1 In contrast to Burnham's concern for visual monumentality and spectacle, Olmsted focused his attention on sociological questions of housing conditions and traffic congestion. This ideological divide between architects, like Burnham, and landscape architects, like Olmsted, was a recurring theme within professional publications of the period. One editorial from a 1911 issue of Landscape Architecture Magazine, for instance, mocked the architects' superficial approach to planning: "[City Beautiful planners] apparently approach the designing of a city much as they might the designing of a rug, considering first its appearance when looked at vertically downward." 2 This sort of rhetoric demonstrates not only the prevalent antagonism between landscape architects and architects during this period, but also a key difference between the two professions' respective approaches to city planning: completion versus adaptability.

Unlike the static, formalist schemes produced by Burnham, landscape architects like Olmsted insisted that a city plan should be understood "as a live thing, as a growing and 
gradually changing aggregation of accepted ideas or projects for physical changes in the city." ${ }^{\prime 3}$ It was this prioritization of social reform and adaptability-as opposed to any specific formal language-that provided the intellectual foundations for landscape architecture. Such a directive ultimately set the emerging profession along a completely different trajectory in the twentieth century than its allied discipline of architecture. And while the architects' formal tastes have changed since the early twentieth century, the general dynamic outlined above continues to hold true. That is, architects remain invested in formal typologies, while landscape architects tend to contextualize their design thinking in relation to ecological and socio-cultural processes.

Given the significant ideological divide between architects and landscape architects, one might wonder how appealing disciplinary hybridization actually is for design professionals. For their part, many contemporary landscape architects do not seem so interested in collaborating, let alone on hybridizing, with architects. In a recent interview with the American Society of Landscape Architects, the acclaimed landscape designer, Kathryn Gustafson, explained the meaning behind her oft-repeated expression, the sky is mine: "I'll go back to my expression, the sky is mine. For all landscape architects, anything under the open sky is a landscape architecture issue." ${ }^{\prime 4}$ In recent lectures, Gustafson has even described her hesitation with allowing the world-renowned architect, David Adjaye, to contribute a design element to her landscape plan for the grounds surrounding Adjaye's National Museum of African American History and Culture in Washington, DC. ${ }^{5}$ These statements and interactions point to an atmosphere of jurisdictional tension and inter-professional competition, rather than a shared interest in hybridizing the respective discourses and methodologies of architecture and landscape architecture.

Meanwhile, one might consider the possibility that architecture's recent interest in "landscape" is not an appeal to the discourses and methodologies of landscape architecture, but instead, a formal fascination with the aesthetics of landscape. As evidence of this point, one need not look any further than all of the trees and plants unrealistically depicted on top of buildings in so many recent architectural renderings. ${ }^{6}$ The presence of this vegetative ornamentation, absent of any consideration for soil depths, climatic factors, or ecological cycles, demonstrates the ways in which contemporary architects understand and employ vegetation as merely another mute component that can contribute to the overall aesthetic effect of a building. Furthermore, it is no coincidence that the recent architectural projects described under the headings of "landform buildings" and "landscrapers" emerged in parallel with digital modeling programs that allowed architects to explore the spatial potential of continuous surfaces. To the skeptical observer, this architectural appropriation of landscape's formal and aesthetic characteristics reduces the rich and layered discipline of landscape architecture to a mere image.

Setting aside the individual motivations of architects and landscape architects, one must consider the fact that the distinction between these two disciplines is the foundation upon which our existing professional infrastructure sits. For this reason, any retroactive hybridization of these two disciplines would necessitate a complete overhaul of our educational structures, contractual frameworks, systems of accreditation and licensure, publication models, professional organizations, and so on. These changes would, in turn, produce even more questions regarding such issues as professional liability, foundational skills, disciplinary canons, and pedagogical techniques, to name a few. Combined with the ideological divide between architects and landscape architects discussed above, this infrastructural inertia makes disciplinary hybridization a uniquely difficult endeavor.

But even if design professionals could overcome the massive infrastructural and ideological obstacles, then there still remains a more fundamental argument against hybridization, which hinges on the political structure of the contemporary city. Since architects tend to work on individual buildings, under the employ of clients from the private sector, they are typically not as involved in the design of public spaces as are their landscape counterparts. This jurisdictional configuration has led to a qualitative difference between the types of work that these two disciplines pursue, as well as their respective roles within the structuring of a city. Furthermore, there are strong political arguments for maintaining the clear division between the public and private spheres of urban life. In fact, the "privatization of public space" has recently been identified as a critical problem within contemporary urban discourse. ${ }^{7}$ In this case, the phenomenon of "privatization" does not merely describe the transformation of previously public spaces into private ones, but also the mis-representation of privately controlled spaces as ostensibly being public. With the revitalization and gentrification of many downtown areas, for example, there has been a swell of commercial projects that masquerade as "public space" but actually operate according to rules and regulations determined and enforced by private entities. One dangerous consequence of this conflation of the public/private distinction is the exclusion of nonnormative bodies and behaviors from these quasi-public spaces, ultimately leading to the gradual homogenization of the city as a whole.

To the extent that the hybridization of architecture and landscape architecture would contribute to the obfuscation of public/private distinctions within urban space, it should be resisted. Taking the argument one step further, one might suggest that architecture has a political responsibility not only to maintain the division between these spheres, but also to make their differences legible. Such a position implicates 
architecture within a politics of representation, wherein the formal qualities of a building and its site-posturing have the potential to reveal cultural systems that often escape our conscious awareness. Furthermore, this essay suggests that ground, more than any other architectural element, plays a central role in exposing or concealing the political and economic orders that structure a city. Therefore, a more productive reframing of the question might set aside the debate over hybridization, which is fraught with a whole range of problematic premises, in order to examine the ways in which architects have conceptualized the ground and its relation to the both the building and the city, at large.

\section{CONTINUOUS GROUNDS}

Since the emergence of architectural modernism in the early twentieth century, many architects have emphasized the continuity of the ground through their work. In his essay, "Human/Nature: Wilderness and the Landscape/ Architecture Divide," Joel Sanders picks up on this rendering of continuity and describes its implications through a discussion of Le Corbusier's Villa Savoye and Mies van der Rohe's Farnsworth House. According to Sanders, the lifting of architecture off of the earth's surface functions to preserve the sanctity of the ground. ${ }^{8}$ Such a dramatic divorce of building from ground was even further exaggerated in several speculative projects of the postwar era, including Aldo Rossi's Teatro del Mundo and John Hejduk's nomadic masques. In these works, the architectural object is conceived as an autonomous stranger, wandering through the city with no place to call home.

While these projects emphasize the continuity of ground by completely severing it from the architectural volume, a parallel line of exploration emerged in the postwar era that collapsed architecture into ground, erasing any trace of the building as an object. Such an approach is evident in Superstudio's Continuous Monument and Archizoom's No-Stop City, as well as a variety of other concurrent speculations on fields and networks. However, it was Peter Eisenman, more than any other architect, who consciously attempted to reimagine buildings through the formal language of ground. In his proposals for Cannaregio, Long Beach, and Castelvecchio, as well as his explication of "artificial excavations," Eisenman diverged from the formal language of his early house studies in favor of a new language of architecturalized topography. These ideas and speculations were eventually realized in several built works, including his Memorial to the Murdered Jews of Europe in Berlin and his City of Culture of Galicia in Santiago de Compostela. In these projects, a language of slopes, chasms, monoliths, and excavated pits replace his earlier configurations of intersecting frames and surfaces. By transposing qualities and characteristics of the ground onto buildings, Eisenman both reaffirms the continuity of ground and subsumes architecture into that continuous stratum.
In recent decades, the formal strategy of merging architecture with ground has become even more common both within architectural schools and the profession, more generally. Such an interest is evident in works of various sizes, uses, and intellectual agendas, including FOA's Yokohama Port Terminal, Renzo Piano's Vulcano Buono, and Emilio Ambasz's Fukuoka Prefectural International Hall, among countless others. Some of these architecture-as-landscape projects render the continuous ground surface with the verdant qualities of natural vegetation, while others present buildings in a continuous relationship with an explicitly man-made ground surface. In any case, these recent architecture-aslandscape projects, along with an array of concomitant texts and theorizations, propose a reality in which buildings are not fundamentally distinct from the ground, and thus the city, that they occupy. Regardless of the formal or aesthetic qualities of these works, the political implications of this radical collapse of architecture into the city through the language of the continuous surface demands further investigation. One way of contemplating these themes and unpacking their political implications is to examine their opposite-that is, to consider the projects that render ground as discrete, rather than continuous.

\section{DISCRETE GROUNDS}

As already noted, Joel Sanders' reading of the Farnsworth House underscores the idea that Mies preserved the ground's continuity by suspending the structure above its flood-prone site. In other instances, however, Mies appears to intentionally call attention to the discontinuity of ground by formally exaggerating the distinction between the ground of the site and the ground of the surrounding city. Such a strategy signals a departure from the conceptions of continuity discussed above by asserting a new conception of ground as discrete. Of course, the primary device that Mies employed to produce his discrete grounds is the plinth. In many of his most celebrated works, including the Neue Nationalgalerie in Berlin, the Seagram Building in New York City, and the German Pavilion in Barcelona, Mies used the plinth to delineate the edge of the site, thereby reinforcing the division between the economic (private) and political (public) orders of the city.

Among the scholars who have considered Mies' application of the plinth, Pier Vittorio Aureli offers the most cogent description of its political implications.

By putting emphasis on the building site, the plinth inevitably makes the site a limit for what it contains... Moreover, the way the plinth reorganizes the connection between a building and its site affects not only one's experience of what is placed on the plinth, but also-and especially-one's experience of the city that is outside the plinth. One of the most remarkable things felt by anyone climbing a Mies plinth, whether in New York or 
in Berlin, is the experience of turning one's back to the building in order to look at the city. Suddenly, and for a brief moment, one is estranged from the flows and organizational patterns that animate the city, yet still confronting them. ${ }^{9}$

As Aureli notes, the discontinuity of ground produced by the Miesian plinth allows one to read architecture against the city. Such a position stands in stark contrast to the intentional blurring, blending, and softening of boundaries that characterize recent "hybridizations" of architecture and landscape. However, to fully understand why Aureli places so much emphasis on the political implications of Mies' plinths, it is necessary to consider his argument in more detail. For Aureli, architectural form serves as an "index for the constitution of an idea of the city. ${ }^{10}$ Furthermore, he argues that "it is precisely in the process of separation inherent in the making of architectural form that the political in architecture lies. ${ }^{\prime 11}$ Understood through this framework, architecture's historical prioritization of form is not merely a disciplinary fetishization, as some would claim, but instead, a practical tactic aimed at producing an "agonistic relationship between architecture and its context." ${ }^{\prime 2}$ To put it another way, this formal discontinuity between architecture and the city, Aureli contends, is a prerequisite for activating architecture's potential to challenge and resist the dominant ideologies that undergird the city as a whole.

To be clear, the definition of autonomy that Aureli invokes in reference to Mies' plinths needs to be distinguished from other theoretical accounts of autonomy that have operated quite differently within twentieth-century discourse. To this end, Casey Haskins' distinction between "strict autonomism" and "instrumental autonomism" is a useful reference point. ${ }^{13}$ Drawing upon Kant's Critique of Judgment, Haskins distinguishes between, on the one hand, works of art that are conceived and evaluated according to their own internal characteristics, and on the other hand, works of art that are conceived independent of their larger sociopolitical and material contexts so that they might operate as agents of change when deployed within those very same contexts. According to Haskins, the former category can be termed "strict autonomism," while the latter is referred to as "instrumental autonomism." Given this distinction, it is clear that Aureli's case for architectural autonomy stems from the instrumental variant, wherein architecture declares its separation from the city as a means for confronting and reshaping the city as both an idea and a reality.

In our current context, one might suggest that architecture's critical potential is needed more than ever before. And, if the implementation of discrete ground conditions can play a role in this reclaiming of architecture's autonomy, then it might be necessary to categorically reject the recent tendency to fuse architecture with the city via the continuous surface.

\section{GROUND OBJECTS}

Given this preliminary argument for discrete ground conditions, one might wonder how the political strategies of a Miesian plinth can be reimagined for the twenty-first century city. In other words, is it possible to identify examples of contemporary architecture that address the ground without establishing a false continuity between architecture and the city? One potential answer to this question can be found in an emerging body of works that treat the ground itself as a designed object. In doing so, these works not only emphasize an external distinction between the architectural ground and the urban ground, but also an internal distinction between the architectural ground and the architectural object.

OMA's Casa da Musica offers a prime example of how strategies of discreteness and discontinuity problematize traditional conceptions of the figure/ground relationship. Positioned at the center of an urban site in Porto, Portugal, the concert hall has the appearance of a massive stone that has been sliced several times at various angles, thereby obscuring any normative reading of directionality (i.e. front, back, side, top). Upon closer examination, one discovers that the ground upon which the building sits is actually a constructed surface, undulating not according to the earth's topography, but instead, according to the architect's intentions. Significantly, the artificial nature of this ground surface is revealed at one corner of the site, where it lifts up to create an entrance in the vertical space between the ground of the city and the constructed ground of the project. Such a moment allows for one to read a tripartite configuration of elements: the urban ground, the architectural ground, and the architectural object.

Thomas Heatherwick's Seed Cathedral, constructed for the Shanghai World Expo in 2010, displays an approach that is similar to OMA's at Casa da Musica, but Heatherwick exaggerates the ground's discreteness even further. Here, the formal qualities of the architectural object and its constructed ground could not be more distinct. On the one hand, the inhabitable pavilion is comprised of thousands upon thousands of fiber optic filaments, each containing the seed of a particular plant species. As a work of architecture, these thin, flexible pieces produce the effect of fuzziness, softening the building's edges and dissolving the legibility of its form. On the other hand, the artificial ground for Heatherwick's Seed Cathedral is a tessellated plane that folds up and down across the surface of its site. Unlike the undulating podium of Casa da Musica, which only peels apart from the urban ground at one corner, Heatherwick's constructed ground is completely autonomous from the ground of the surrounding city. In fact, as visitors move around the edges of the project, they are invited to study its tessellated underbelly. Such an objectification of ground not only reinforces the formal distinction between architecture and its context, but also positions the project in relation to philosophical lineages 
that challenge the presumption that ground is a stabilizing structure for the production of meaning.

Alongside OMA and Heatherwick, Tom Wiscombe has advocated for discrete "ground objects" that mediate between a building's mass and the ground of the city. In an essay published in the architectural journal, Project, Wiscombe characterizes his ground objects as "the total objectification of the land underneath a building." ${ }^{14}$ In this same essay, he goes on to describe three potential strategies for addressing ground-hovering, nestling, and deferring-all of which, he contends, are preferable to the false continuity of the so-called "landscape building." ${ }^{15}$ Wiscombe's theoretical argument for discrete ground conditions, which draws upon certain aspects of Object Oriented Ontology, is illustrated through a range of (mostly unbuilt) building proposals. For instance, his entry for the Guggenheim Helsinki competition features a crystalline mass sitting atop its own architecturalized podium. Then, in a proposal for the National Center for Contemporary Arts in Moscow, Wiscombe places his building upon a thin ground object that peels up to emphasize its discontinuity with the earth.

For Wiscombe, the strategy of distinguishing between the architectural ground and what he calls the "literal ground" has been consciously integrated into his working methodology. In a recent interview published in Offramp 11, he expressed his feeling that "the idea of architecture as landscape is now exhausted," arguing that "the confusion of the two actually degrades the both and kills their specificity as concrete entities." ${ }^{16}$ However, when pressed about the similarity of his position on discreteness to that of Pier Vittorio Aureli, Wiscombe provided a surprising response:

In his theory of the "archipelago," which is ultimately about the ontological status of architecture in cities, [Aureli] imagines that the parts, or islands, are linked by the "common ground" of the city. While I am in basic agreement that architecture can only happen in a state of separation, and I share his desire to carve out space for architecture by refusing the generalizing smoothness of the modern city and its smooth capital exchanges, I do not think that there is such a thing as a common ground that ultimately unites all of the islands. Whether this is meant literally, as in the political land underneath the city, or figuratively, in terms of public and private social systems that connect things, I'd want to avoid presuming the existence of a real connective entity where there is none present. ${ }^{17}$

This exchange highlights the fact that Wiscombe's interest in discreteness stems from his desire to develop a formal language that challenges traditional part-to-whole relationships in architecture, rather than any political motivation (as Aureli would have it) to use architecture as a means for "confronting" the city. Nonetheless, one could argue that Wiscombe's discrete grounds, along with those produced by OMA and Thomas Heatherwick, operate as political gestures whether they were intended to or not. After all, what more powerful way could an architect challenge the "generalizing smoothness" of contemporary urbanism than to suggest that the city, as a unified system, does not exist? By rejecting the very existence of the modern city, Wiscombe carves out a space to think about architecture on its own terms. One compelling result of this theoretical operation is a formal vocabulary for architecturalized grounds that neither collapse into the horizontal stratum of the city nor rely on the misappropriation of landscape architecture.

\section{CONCLUSION}

In an age when the intrinsic value of interdisciplinarity goes largely unquestioned, arguments for the hybridization of architecture and landscape design continue to proliferate. Aside from the substantial ideological and institutional challenges posed by hybridization, this essay contends that architecture's disciplinary autonomy serves a political function within contemporary urban space. Building upon Pier Vittorio Aureli's argument for an agonistic relationship between architecture and the city, I have attempted to identify formal strategies that account for the ground while, at the same time, resisting the tendency to smooth over or erase the boundaries and edges that delineate the jurisdictional sphere of architectural production. Thus, by tracing a lineage of discrete ground conditions from the Miesian plinth to contemporary "ground objects," the essay implicates architectural form within a politics of representation. Rather than co-opting the formal language of landscape-via the continuous surface-I argue that architects should focus their efforts on developing architectural strategies for the ground that emphasize the profound difference between public and private space. Without this distinction, cities are doomed to become sites of ossified homogeneity, devoid of the tensions and conflicts that give them life.

\section{ENDNOTES}

1 In his book, The Struggle for Modernism: Architecture, Landscape, and City Planning at Harvard, Anthony Alofsin describes the student projects executed under Olmsted's leadership: "Student schemes, though often awkwardly executed, demonstrated reformist attitudes that acknowledged the need for community facilities such as parks and playgrounds. Their work reflected an increased interest in the subdivision of land and the already-established practices of eminent domain, which allow the appropriation of property for public welfare. While the echelons of high society suffered no lack of competent designers, civic awareness entered the consciousness of the faculty and students at the Department of Landscape Architecture; this new awareness stimulated new approaches to urban and regional problems that went beyond the scope and benefit of the individual." Anthony Alofsin, The Struggle for Modernism: Architecture, Landscape Architecture, and City Planning at Harvard. New York: W.W. Norton \& Co., 2002), 39-40.

2 "Editorial: City Planning in America," Landscape Architecture Magazine 1, no. 4 (July 1911): 37

3 Fredrick Law Olmsted, Jr., "A City-Planning Program," Journal of the American Institute of Architects 1, no. 6 (June 1913), 233.

4 Kathryn Gustafson, interview by Jared Green. American Society of Landscape Architecture, accessed September 2017. http://www.asla.org/contentdetail. aspx?id=26846. 
5 For example, Gustafson discussed this hesitation regarding inter-professional collaboration at a public lecture at the University of Southern California on February 8, 2017.

6 For more detailed analysis of this strange new trend, see Kurt Kohlstedt, "Renderings vs. Reality: The Improbable Rise of Tree-Covered Skyscrapers," 99\% Invisible, accessed September 2017. http://99percentinvisible.org/article/ renderings-vs-reality-rise-tree-covered-skyscrapers/

7 For more on this phenomenon, see The Politics of Public Space, edited by Setha Low and Neil Smith (New York: Routledge, 2006) and Jeremy Németh and Stephen Schmidt, "The Privatization of Public Space: Modeling and Measuring Publicness," Environment and Planning B: Urban Analytics and City Science 38, no. 1 (February 2011): 5-23.

8 For more detailed discussion of the role of landscape within modern architecture, see Joel Sanders, "Human/Nature: Wilderness and the Landscape/Architecture Divide," in Groundwork: Between Landscape and Architecture, edited by Diana Balmori and Joel Sanders, 12-31. New York: Monacelli, 2011.

9 Pier Vittorio Aureli, The Possibility of an Absolute Architecture (Cambridge, MA: MIT Press, 2011), 37

10 Ibid., ix

11 Ibid.

12 Ibid.

13 For more detailed analysis of autonomy in art, see Casey Haskins, "Kant and the Autonomy of Art," Journal of Aesthetics and Art Criticism 47, no. 1 (1989): 43-54.

14 Tom Wiscombe, "Discreteness, or Towards a Flat Ontology of Architecture," Project 3 (Spring 2014), 41.

15 Ibid., 39-41.

16 "Tom Wiscombe Interviewed by Zachary Tate Porter," Offramp 11: "Ground" edited by Zachary Tate Porter (Spring/Summer 2016), accessed September 2017. http://sciarc-offramp.info/ground/interview-with-zachary-tate-porter

17 Ibid. 